\title{
Personal data and the property of self
}

\section{Bernard Perbal $^{1}$}

Published online: 5 March 2019

(C) The International CCN Society 2019

The dazzling growth of biological sciences, whose societal impacts might not have been well enough anticipated by the international law, has created conceptual conflicts that should be apprehended in constructive debates, respectful of the richness of individual differences, so as to avoid any ideological compartmentalization, which will be of no benefit to Humanity.

The analysis of the roots of the concept of personal data and of the evolution of its acceptance, sends back to the very long and difficult journey from the very first European founding texts to the consecration of the right to privacy rooted in the obstinacy of its two defenders Samuel Warren and Louis Brandeis whose seminal works have impacted international law as a whole.

Personal information identified as data, has become coveted resources by the worlds of economy, electronic business, biomedicine and criminology. The dematerialization of individual characteristics brought with it an immense wave of issues and conflicts in relation with procedures of collection, processing, circulation and confidentiality of this type of data, especially when it dealt with sensitive identifiers such as genetic data.
Technically unattainable until now, the secrets of life and heredity are currently being offered to the general public, who often finds itself powerless when facing companies willing to exploit the richness of their intimate self.

The newly revealed potentialities of human genetic engineering, has put forth the weakness and inefficiencies of outdated legal and normative texts which, because of their inadequacy to societal evolution, lead to rigid divisions of principles before genetic technologies who aspire to take advantage of the understanding of genomes in order to improve the well being of people.

It is necessary, today, to remove any passionate feeling to temper emotional debates by redefining, as soon as possible, the legal status of genetic data and the information that their exploitation can deliver.

Publisher's note Springer Nature remains neutral with regard to jurisdictional claims in published maps and institutional affiliations.
Bernard Perbal

bperbal@gmail.com

1 Université de Nice Sophia-Antipolis, Nice, France 